\title{
Focus in Honor of Gary J. Van Berkel, 2005 Biemann Medal Awardee
}

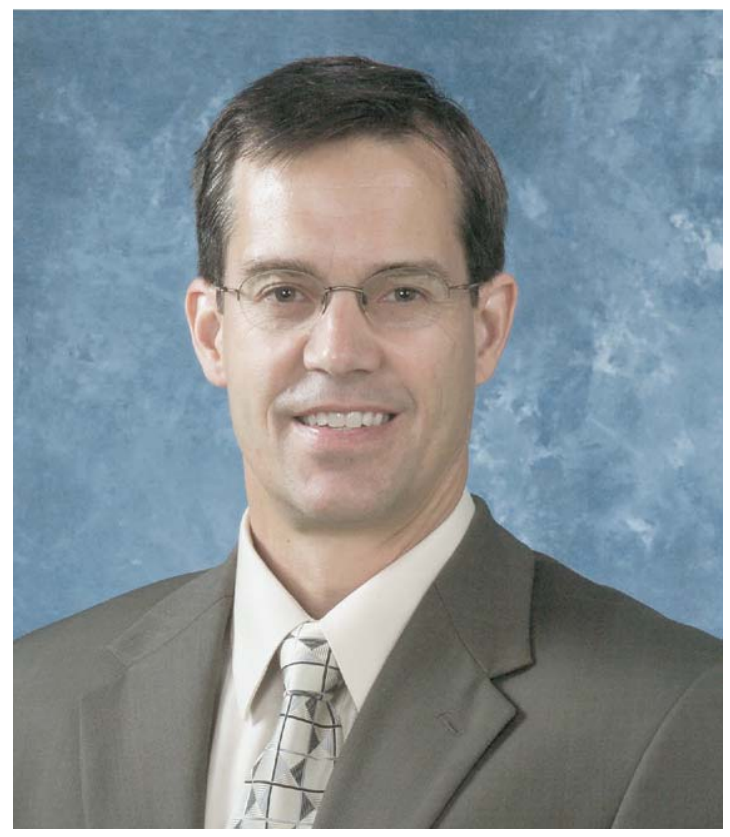

I n 1987 Scott McLuckey and I were looking for a postdoctoral associate to join our growing Organic Mass Spectrometry group at Oak Ridge National Laboratory. This was to be the first post doctoral associate whom we hired, and we wanted to get the best scientist we could find. One person stood out from the pool of applicants, a candidate from Washington State University whose background was in the area of porphyrin analysis, but he had little mass spectrometry experience. This candidate was very enthusiastic about learning mass spectrometry as a means to increase his capabilities for porphyrin analysis and was adamant that our group was the best place for him to learn. Because of the relationship of porphyrins to oil, we thought that might be a way we could expand our funding as a Department of Energy laboratory. So we hired Gary Van Berkel as our first postdoctoral associate.

Initially, Gary worked mainly on analysis of porphyrins using mass spectrometry. He also got involved in some of the early quadrupole ion trap development work in our laboratory. A critical juncture in Gary's

Published online May 12, 2006

Address reprint requests to Dr. Gary L. Glish, Department of Chemistry, University of North Carolina, CB \#3290, Chapel Hill, NC 27599, USA. E-mail: glish@unc.edu career path occurred in early 1989. After I returned from the Sanibel Conference on Desorption Ionization, Gary, Scott, and I had a discussion about the new ionization techniques and decided we should try to implement electrospray ionization on a quadrupole ion trap. Gary volunteered to take the lead in putting together an apparatus, using our atmospheric-sampling, glow-discharge ionization source as the platform. At the time that work was being done, Scott and I fought one of our many battles with the ORNL bureaucracy, to convert Gary to a permanent staff member at ORNL. There was a policy that post doctoral associates could not be subsequently hired as permanent staff members, even though the standards for hiring a post doc were the same as hiring a staff member. Fortunately for us and for ORNL, we prevailed and Gary became a permanent staff member in 1989.

After getting electrospray interfaced to a quadrupole ion trap, Gary, of course, applied it to the analysis of porphyrins. But he also developed an interest in the fundamentals of electrospray, and using his well rounded analytical skills, he recognized the importance of electrochemistry in the ionization process. He took the lead in studies of various aspects of electrochemistry and electrospray, from fundamentals to development of analytical methods, to take advantage of electrochemical reactions. 
Jumping forward to 2005, Gary has become recognized as a leading expert in the area of electrospray and was awarded the Biemann Medal for his work involving electrochemistry and electrospray. He is now the group leader of the Organic and Biological Mass Spectrometry group at ORNL and has expanded his research into a number of areas involving mass spectrometry (porphyrin analysis is not listed on his webpage, but I am sure it is something that will always be dear to his heart).

The focus section in this issue of the Journal is to honor Gary as the Biemann Medal recipient. While it is customary to have articles related to the area of work for which the award was given, we have done something different here because there was a recent issue with a focus section on electrochemistry combined with mass spectrometry (December 2004, organized by Gary). Gary has always recognized the value of working with other scientists who have knowledge that complements his. Thus, he has had many collaborators over the years; so we invited past and present collaborators and colleagues to submit articles for this focus issue. We had a large number of people who wanted to contribute articles (and pictures), but timing prevented a number of these people from submitting articles. Thus, this focus consists of eight articles, half from former ORNL colleagues and half from current colleagues. There is not a specific scientific area that is spotlighted, but the eight articles fall into one of two general categories: ion trapping or electrochemistry combined with mass spectrometry. In retrospect, since these are two of the main areas in which Gary has been involved, it is understandable that these should be areas of interest to his collaborators.

In the area of ion trapping there are five articles. A current and long-time colleague of Gary, Doug Goeringer, has been a major contributor to theoretical understanding of quadrupole ion traps and continues work in that area. His contribution is "Prediction of Collective Characteristics for Ion Ensembles in Quadrupole Ion Traps Without Trajectory Simulations." Greg Hurst and Bob Hettich, who are members of Gary's group and have been the driving force behind FT-ICR research at ORNL for many years, have an article "Determination of Peptide and Protein Ion Charge States by Fourier Transformation of Isotope-Resolved
Mass Spectra." Former ORNL colleague, Steve Lammert, who has always had an interest in ion trap instrument development, has contributed and article on new ion trap design, "Miniature Toroidal Radio Frequency Ion Trap Mass Analyzer." Gary's former mentor and ORNL colleague, Scott McLuckey, now at Purdue University, has contributed an article, "Ion Trap Collision-Induced Dissociation of Human Hemoglobin $\alpha$-Chain Cations" that continues his group's development of top-down proteomics using quadrupole ion traps. The final ion trap paper, "Determination of Cooling Rates in a Quadrupole Ion Trap" comes from my group at the University of North Carolina and addresses a fundamental aspect of quadrupole ion trap operation.

In the area of electrochemistry combined with mass spectrometry, Doug Duckworth, a long-time colleague of Gary, working in inorganic mass spectrometry at ORNL, contributed an article "Electrochemically-Induced Reactions of Hexafluorophosphate Anions with Water in Negative Ion Electrospray Mass Spectrometry of Undiluted Ionic Liquids." Feimeng Zhou, whose graduate training was in electrochemistry, was the first postdoctoral associate Gary hired specifically to work on electrochemistry combined with mass spectrometry, and he has continued working in that area as a faculty member at California State University, Los Angeles. Feimeng contributed an article entitled "Nafion-Coated Bismuth Film and Nafion-Coated Mercury Film Electrodes for Anodic Stripping Voltammetry Combined On-Line with ICP-Mass Spectrometry". The last article in this group "Expanded Use of a Battery-Powered Two-Electrode Emitter Cell for Electrospray Mass Spectrometry" comes from one of Gary's current post docs, Vilmos Kertesz, and is coauthored by Gary.

It was a pleasure to organize this focus issue to honor Gary, and it was a pleasure to work with him for five years before I left ORNL. We coauthored 18 papers during that time and Gary's science and data were always of the very highest quality. With a long career still ahead of him, I have no doubt that outstanding science will continue to come from Gary's laboratory for many years.

Gary L. Glish

Department of Chemistry, University of North Carolina, Chapel Hill, North Carolina, USA 